\title{
Effects of operating variables on the induction period of $\mathrm{CaCl}_{2}-\mathrm{Na}_{2} \mathrm{CO}_{3}$ system
}

\author{
Clifford Y. Tai, Wen-Chen Chien* \\ Department of Chemical Engineering, National Taiwan University, Taipei 10617, Taiwan
}

\begin{abstract}
The induction period is defined as the time elapsed between the creation of supersaturation and the formation of critical nuclei. A novel data acquisition system is developed in this experiment to determine the induction period on the desupersaturation curve. The effect of several operating conditions, including initial reagent concentration, temperature, $\mathrm{pH}$, and presence of additive and seeds on the induction period of $\mathrm{CaCO}_{3}$ were studied experimentally. The results showed that the induction period decreases with an increase in initial reagent concentration, temperature, and $\mathrm{pH}$ of the solution. The presence of $\mathrm{Mg}^{2+}$ in solution prolongs the induction period. On the other hand, the presence of $\mathrm{Na}^{+}$in solution has little influence on the induction period. Further, the presence of seed crystals in solution shortens the induction period. (C) 2002 Published by Elsevier Science B.V.
\end{abstract}

Keywords: A1. Impurities; A1. Nucleation; A1. Supersaturated solutions; B1. Calcium compounds; B1. Inorganic compounds; B1. Minerals

\section{Introduction}

The induction period, $t_{\text {ind }}$, is defined as the time that elapses between the creation of supersaturation, $S_{\mathrm{a}}$, and the formation of critical nuclei. Many methods have been applied for the determination of induction period, including the conductivity method [1,2], intensity of transmitted or scattered light method [3-5], heat released method [6,7], activity of precipitated ions method [8] and $\mathrm{pH}$ method [9]. Among the proposed methods, the conductivity method is frequently used to measure both long and short induction periods due to its good stability and sensitivity. According to this method, the end of the induction period is

\footnotetext{
*Corresponding author. Fax: + 886-2-236-23040.

E-mail address: wcchien@kimo.com.tw (W.-C. Chien).
}

determined as the time when the slope of the desupersaturation curve, which is a plot of solution conductivity against time curve, starts to change [10]. However, by using the conductivity method the induction period is not usually clearly determined on the desupersaturation curve. Thus, a novel data acquisition system is applied in a previous study [11] so that the induction period can be easily estimated from the enlarged desupersaturation curve.

Since the induction period is closely related to the metastable zone width and nucleation rate of a system, many efforts have been devoted to this area. As a result, several important operating variables such as supersaturation, temperature, $\mathrm{pH}$, agitation speed, and impurity $[1,2,9,12,13]$ are found to have an influence on the induction period. So far, the effects of these variables on 
the induction period of $\mathrm{CaCO}_{3}$ in the $\mathrm{CaCl}_{2}-$ $\mathrm{Na}_{2} \mathrm{CO}_{3}$ system are not systematically studied. Therefore, in this article we investigated experimentally the effects of several operating variables, including initial reagent concentration, temperature, $\mathrm{pH}$, and presence of additive and seeds, on the induction period of $\mathrm{CaCO}_{3}$ in the aqueous $\mathrm{CaCl}_{2}-\mathrm{Na}_{2} \mathrm{CO}_{3}$ solution, using a conductivity meter linked with the novel data aquisition system.

\section{Experimental procedure}

The experimental apparatus, which consists mainly of three parts: (I) reagent feeding system, (II) crystallizer with temperature control, and (III) data acquisition system, has been reported in a previous study [11]. Guaranteed grade calcium carbonate (Nacalai Tesque), extra-pure grade anhydrous sodium carbonate (Nacalai Tesque), extra-pure magnesium chloride hexahydrate and sodium chloride (Nacalai Tesque), and high quality deionized water with a specific resisitivity $18 \mathrm{M} \Omega \mathrm{cm}$ were used. The water was filtered through a $0.2 \mu \mathrm{m}$ filter before use. The experimental conditions, including vessel size, type, and material of construction, and agitation rate are maintained constant.

The experimental procedures are described briefly below. A desired quantity of water and $0.1 \mathrm{M} \mathrm{CaCl}_{2}$ solution were poured into the glass beaker and mixed by a magnetic stirrer to form a solution of specified concentration. After the solution temperature became steady at $25^{\circ} \mathrm{C}$ and the conductivity remained constant for several minutes, a required quantity of $0.1 \mathrm{M} \mathrm{Na} \mathrm{NaO}_{3}$ solution at $25^{\circ} \mathrm{C}$ was added into the beaker. The solution conductivity increased rapidly to a high level and stayed there for a certain period of time once the mixing is complete. Then, a decrease in conductivity was observed while the solution was still clear. Afterwards, the solution became turbid as detected by naked eyes. The experiment was stopped after the conductivity had no more significant change. After each run, the experimental apparatus was rinsed with $0.1 \mathrm{M}$ aqueous $\mathrm{HCl}$ solution to remove residual precipitate.

In the case in which the $\mathrm{pH}$ effect is investigated, the procedure differs from the previous case in having the $0.1 \mathrm{M}$ aqueous $\mathrm{HCl}$ solution added into the $\mathrm{CaCl}_{2}-\mathrm{Na}_{2} \mathrm{CO}_{3}$ system to adjust the solution $\mathrm{pH}$. In all runs, the solution temperature is at $25^{\circ} \mathrm{C}$ with no seed crystal existing in the aqueous solution. The solution $\mathrm{pH}$ investigated in the present work ranges from 8.84 to 10.85 .

In the case in which the additives effect is investigated, a desired quantity of $0.1 \mathrm{M}$ aqueous $\mathrm{MgCl}_{2}$ (or $\mathrm{NaCl}$ ) solution as the source of $\mathrm{Mg}^{2+}$ (or $\mathrm{Na}^{+}$) was added into the solution in beaker before the addition of $0.1 \mathrm{M}$ aqueous $\mathrm{Na}_{2} \mathrm{CO}_{3}$ solution. Other experimental procedure is the same as the previous case. In all runs, the solution temperature is at $25^{\circ} \mathrm{C}$ with no seed crystal existing in the aqueous solution. The molar concentration ratio between $\mathrm{Mg}^{2+}$ and $\mathrm{Ca}^{2+},\left[\mathrm{Mg}^{2+}\right] /\left[\mathrm{Ca}^{2+}\right]$, investigated in the present work ranges from 0.2 to 1.0. On the other hand, the molar concentration ratio between $\mathrm{Na}^{+}$and $\mathrm{Ca}^{2+},\left[\mathrm{Na}^{+}\right] /\left[\mathrm{Ca}^{2+}\right]$, ranges from 0.57 to 8.57 .

In the case of seeded experiment, the procedure differs only in having the seed crystals placed in the solution. The seed crystals with a size of 355 $425 \mu \mathrm{m}$ and total weight of $0.11-0.13 \mathrm{~g}$ are added into the solution before the $0.1 \mathrm{M}$ aqueous $\mathrm{Na}_{2} \mathrm{CO}_{3}$ solution is added.

Typical desupersaturation curves represented by curve (a) for the aqueous $\mathrm{CaCl}_{2}-\mathrm{Na}_{2} \mathrm{CO}_{3}-\mathrm{MgCl}_{2}$ solution and curve (b) for the aqueous $\mathrm{CaCl}_{2}-$ $\mathrm{Na}_{2} \mathrm{CO}_{3}$-seed solution at $25^{\circ} \mathrm{C}$ are shown in Fig. 1 . The typical desupersaturation curves of pure aqueous $\mathrm{CaCl}_{2}-\mathrm{Na}_{2} \mathrm{CO}_{3}$ system and the important features of the desupersaturation curves have been described elsewhere [11]. The $t_{\text {ind }}$ is identified by the change of conductivity as shown in Fig. 2, which is an enlarged figure of the part for time interval between 0 and 180 s shown in Fig. 1.

\section{Results and discussion}

Fig. 3 illustrates the experimental data of induction period obtained at various initial reagent concentrations of $\mathrm{CaCl}_{2}$ and $\mathrm{Na}_{2} \mathrm{CO}_{3}$ for the unseeded and seeded case. The results show that the induction period of $\mathrm{CaCO}_{3}$ decreases exponentially with an increase in initial reagent concentration at constant temperature for both 


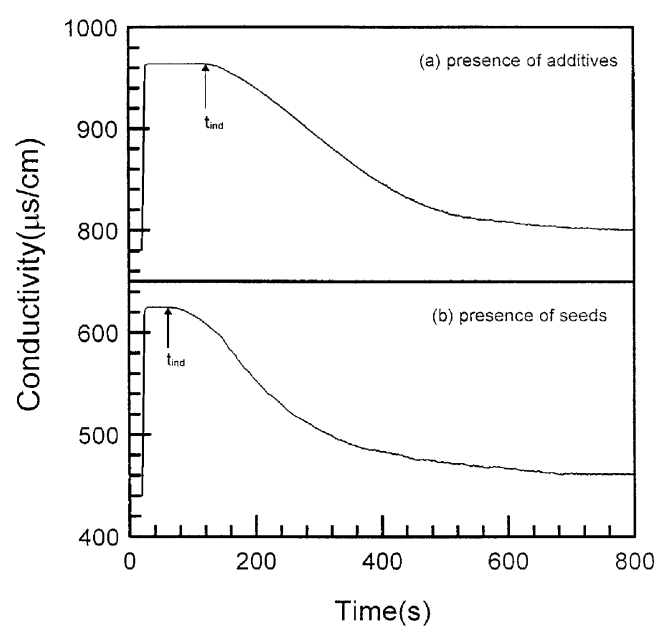

Fig. 1. Typical desupersaturated curves for the two different operating conditions at $25^{\circ} \mathrm{C}$ : (a) $\left[\mathrm{CaCl}_{2}\right]_{i}=\left[\mathrm{Na}_{2} \mathrm{CO}_{3}\right]_{i}=$ $0.0035 \mathrm{M}$, and $\left[\mathrm{MgCl}_{2}\right]=0.0021 \mathrm{M}$ and (b) $\left[\mathrm{CaCl}_{2}\right]_{i}=\left[\mathrm{Na}_{2} \mathrm{CO}_{3}\right]_{i}=$ $0.0025 \mathrm{M}$, seed weight $=0.1107 \mathrm{~g}$, and seed size $=355-425 \mu \mathrm{m}$.

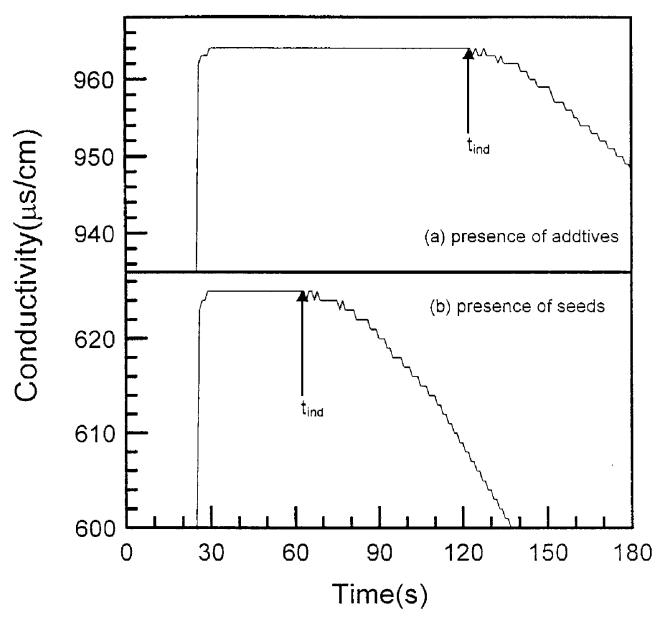

Fig. 2. (a) Enlarged conductivity-time curves showing $t_{\text {ind }}$ for the cases $\left[\mathrm{CaCl}_{2}\right]_{i}=\left[\mathrm{Na}_{2} \mathrm{CO}_{3}\right]_{i}=0.0035 \mathrm{M}$, and $\left[\mathrm{MgCl}_{2}\right]_{i}=$ $0.0021 \mathrm{M}$. (b) Enlarged conductivity-time curves showing $t_{\text {ind }}$ for the case $\left[\mathrm{CaCl}_{2}\right]_{i}=\left[\mathrm{Na}_{2} \mathrm{CO}_{3}\right]_{i}=0.0025 \mathrm{M}$, seed weight $=0.1107 \mathrm{~g}$, and seed size $=355-425 \mu \mathrm{m}$.

unseeded and seeded case. The results of unseeded case are the same as those obtained by Söhnel and Mullin [1] at higher initial concentration of $\mathrm{CaCl}_{2}$ and $\mathrm{Na}_{2} \mathrm{CO}_{3}$. For a given level of initial reagent concentration of $\mathrm{CaCl}_{2}$ and $\mathrm{Na}_{2} \mathrm{CO}_{3}$, the induction periods of seeded case are shorter than the

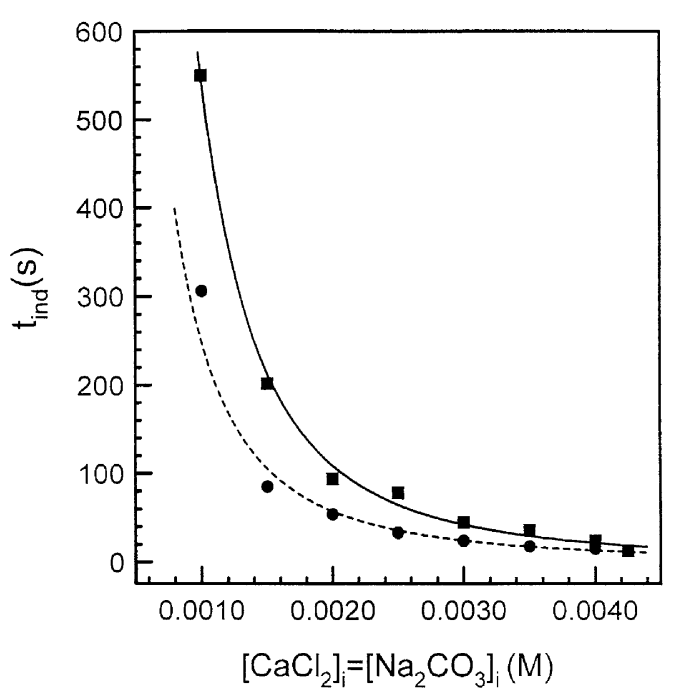

Fig. 3. Induction period as a function of initial reagent concentration of $\mathrm{CaCl}_{2}$ and $\mathrm{Na}_{2} \mathrm{CO}_{3}$ for unseeded and seeded cases at $25^{\circ} \mathrm{C}$ : $\mathbf{D}$ experimental point for unseeded case and $\bullet$ experimental point for seeded case.

corresponding induction period of unseeded case. The induction period has frequently been used as a measure of the nucleation event and it can be considered to be inversely proportional to the rate of nucleation derived from classical nucleation theory under simplified assumption [14]

$\log t_{\text {ind }} \propto\left[\frac{\gamma^{3}}{T^{3}\left(\log S_{\mathrm{a}}\right)^{2}}\right]$.

Eq. (1) shows that the interfacial energy, $\gamma$, temperature, $T$, and supersaturation, $S_{\mathrm{a}}$, are the important factors, which can affect the induction period, $t_{\text {ind }}$. Therefore, the decrease in induction period at higher reagent concentration for both unseeded and seeded case can be interpreted as the increase in supersaturation at constant temperature and interfacial energy as shown in Eq. (1). On the other hand, the shorter induction periods of seeded case than that of unseeded case at a given level of initial reagent concentration is caused by the creation of an interfacial supersaturation near the surface of seeds. Due to the adsorption of solute clusters, the interfacial supersaturation is higher than the bulk supersaturation. Therefore, the addition of seeds in solution causes a decrease in induction period. Qian and Botsaris [15] indicate that the decrease in induction period of 
seeded case is mainly caused by higher coagulation concentration of clusters in the region near the seed crystal. The higher coagulation concentration of clusters in the region near the seed crystal results from the van der Waals attractive force between the cluster and seed. Recently, Kuznetsov et al. [16] has also indicated that at the vicinity of a crystal has a relatively high supersaturation than bulk solution in their study by using the atomic force microscopy on protein. Fig. 4 shows that the induction period as a function of initial reagent concentrations of $\mathrm{CaCl}_{2}$ and $\mathrm{Na}_{2} \mathrm{CO}_{3}$ at three different levels of temperature, i.e., $15^{\circ} \mathrm{C}, 25^{\circ} \mathrm{C}$, and $35^{\circ} \mathrm{C}$. The experimental results show that the induction periods decrease exponentially with an increase in initial reagent concentration of $\mathrm{CaCl}_{2}$ and $\mathrm{Na}_{2} \mathrm{CO}_{3}$ for all levels of temperature. For a given level of initial reagent concentration of $\mathrm{CaCl}_{2}$ and $\mathrm{Na}_{2} \mathrm{CO}_{3}$, the induction period decreases with an increase in temperature. The results are the same that reported by Mullin and Žáček [13] in the precipitation study of potassium aluminum sulphate over the temperature range $15-35^{\circ} \mathrm{C}$. According to the classical nucleation theory they concluded that the decrease in induction period at higher solution temperature is not only caused by

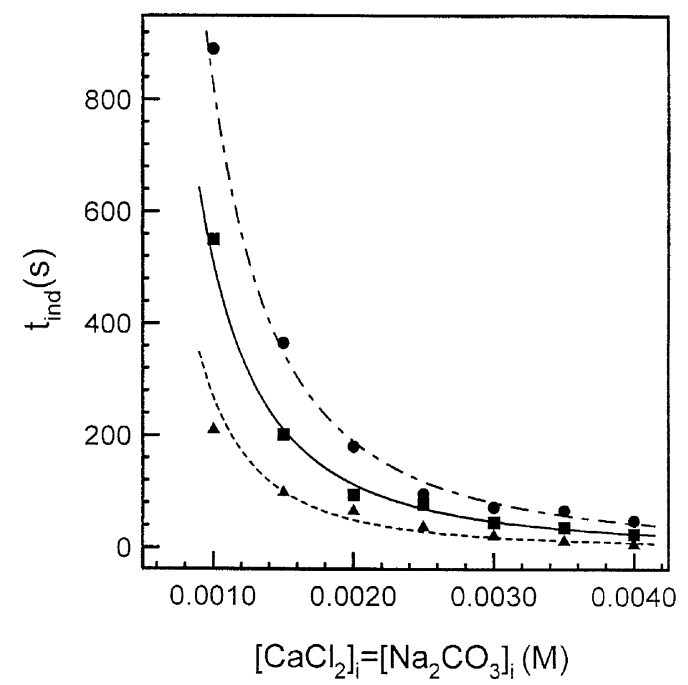

Fig. 4. $t_{\text {ind }}$ as a function of initial reagent concentration of $\mathrm{CaCl}_{2}$ and $\mathrm{Na}_{2} \mathrm{CO}_{3}$ at three different levels of solution temperature: $\bullet$ experimental point for $T=15^{\circ} \mathrm{C}$; $\square$ experimental point for $T=25^{\circ} \mathrm{C}$ and $\diamond$ experimental point for $T=35^{\circ} \mathrm{C}$. the effect of temperature as shown in Eq. (1) but also by the smaller interfacial energy of crystal at higher solution temperature. Fig. 5 illustrates the experimental data of induction period obtained at various levels of $\mathrm{pH}$ and three different initial reagent concentrations of $\mathrm{CaCl}_{2}$ and $\mathrm{Na}_{2} \mathrm{CO}_{3}$, i.e., $0.0015,0.0025$ and $0.0035 \mathrm{M}$. Fig. 5 indicates that $t_{\text {ind }}$ decrease exponentially with an increase in solution $\mathrm{pH}$ for all levels of initial concentrations of $\mathrm{CaCl}_{2}$ and $\mathrm{Na}_{2} \mathrm{CO}_{3}$. For a given level of solution $\mathrm{pH}$, the induction period decreases with an increase in initial reagent concentration of $\mathrm{CaCl}_{2}$ and $\mathrm{Na}_{2} \mathrm{CO}_{3}$. The decrease in induction period at higher solution $\mathrm{pH}$ is mainly caused by the higher supersaturation, which is resulted from a higher concentration of $\mathrm{CO}_{3}^{2-}$ in solution. The supersaturation is related to the concentration of $\mathrm{CO}_{3}^{2-}$, which is a function of $\mathrm{pH}$ at a fixed initial concentration of total carbonate [17]. Fig. 6 illustrates the experimental data of induction period obtained at different mole concentration ratios of $\left[\mathrm{Mg}^{2+}\right] /\left[\mathrm{Ca}^{2+}\right]$ under four different levels of initial reagent concentration of $\mathrm{CaCl}_{2}$ and $\mathrm{Na}_{2} \mathrm{CO}_{3}$, i.e., $0.0040,0.0035,0.0025$ and $0.0015 \mathrm{M}$. The experimental results show that the induction periods increase with an increase in

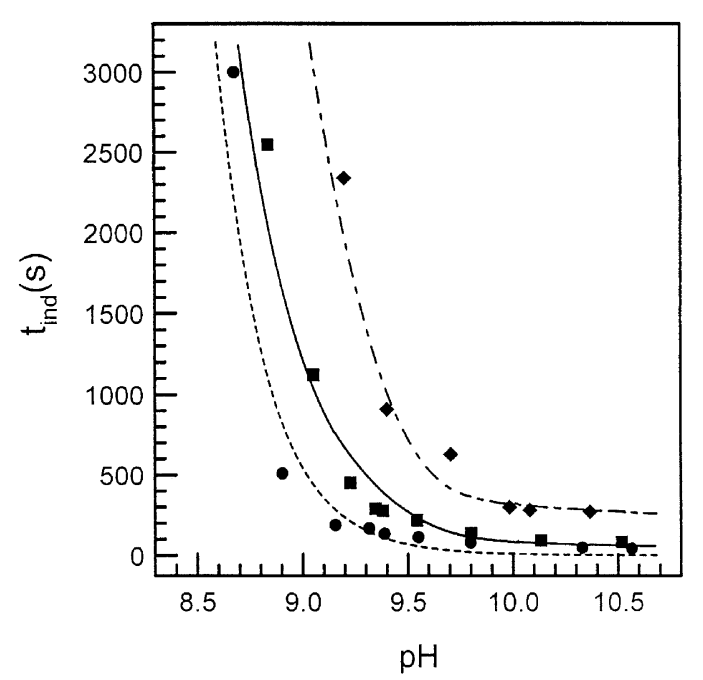

Fig. 5. $t_{\text {ind }}$ as a function of solution $\mathrm{pH}$ at three different initial reagent concentrations of $\mathrm{CaCl}_{2}$ and $\mathrm{Na}_{2} \mathrm{CO}_{3}$ at $25^{\circ} \mathrm{C}$ : experimental point for $\left[\mathrm{CaCl}_{2}\right]_{i}=\left[\mathrm{Na}_{2} \mathrm{CO}_{3}\right]_{i}=0.0015 \mathrm{M}$; experimental point for $\left[\mathrm{CaCl}_{2}\right]_{i}=\left[\mathrm{Na}_{2} \mathrm{CO}_{3}\right]_{i}=0.0025 \mathrm{M}$ and experimental point for $\left[\mathrm{CaCl}_{2}\right]_{i}=\left[\mathrm{Na}_{2} \mathrm{CO}_{3}\right]_{i}=0.0035 \mathrm{M}$. 


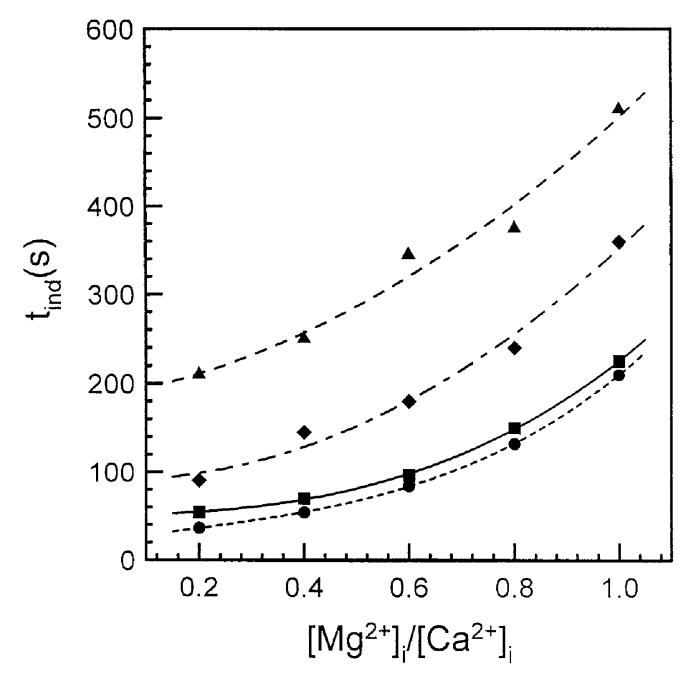

Fig. 6. The effect of concentration ration $\left[\mathrm{Mg}^{2+}\right] /\left[\mathrm{Ca}^{2+}\right]$ on the induction period at different initial reagent concentration of $\mathrm{CaCl}_{2}$ and $\mathrm{Na}_{2} \mathrm{CO}_{3}$ : $\boldsymbol{\Delta}$ experimental point for $\left[\mathrm{CaCl}_{2}\right]_{i}=$ $\left[\mathrm{Na}_{2} \mathrm{CO}_{3}\right]_{i}=0.0015 \mathrm{M} ; \bullet$ experimental point for $\left[\mathrm{CaCl}_{2}\right]_{i}=\left[\mathrm{Na}_{2}\right.$ $\left.\mathrm{CO}_{3}\right]_{i}=0.0025 \mathrm{M} ; \mathbf{\square}$ experimental point for $\left[\mathrm{CaCl}_{2}\right]_{i}=\left[\mathrm{Na}_{2}\right.$ $\left.\mathrm{CO}_{3}\right]_{i}=0.0035 \mathrm{M}$ and $\bullet$ experimental point for $\left[\mathrm{CaCl}_{2}\right]_{i}=$ $\left[\mathrm{Na}_{2} \mathrm{CO}_{3}\right]_{i}=0.0040 \mathrm{M}$.

$\left[\mathrm{Mg}^{2+}\right] /\left[\mathrm{Ca}^{2+}\right]$ for all levels of initial reagent concentration of $\mathrm{CaCl}_{2}$ and $\mathrm{Na}_{2} \mathrm{CO}_{3}$. For a given level of $\left[\mathrm{Mg}^{2+}\right] /\left[\mathrm{Ca}^{2+}\right]$, the induction period decreases with an increase in initial reagent concentration of $\mathrm{CaCl}_{2}$ and $\mathrm{Na}_{2} \mathrm{CO}_{3}$. On the other hand, the addition of $\mathrm{Na}^{+}$in solution has little influence on the induction period of $\mathrm{CaCO}_{3}$. The mole concentration ratio of $\left[\mathrm{Na}^{+}\right] /\left[\mathrm{Ca}^{2+}\right]$ investigated in the present work ranges from 0.57 to 8.57 at a fixed initial reagent concentration of $\mathrm{CaCl}_{2}$ and $\mathrm{Na}_{2} \mathrm{CO}_{3}$, i.e., $0.0035 \mathrm{M}$. In general, the presence of impurities in a system can affect the induction period considerably, but it is virtually impossible to predict. Some impurities increase the induction period, whereas others may decrease it or have no effect. The effect of impurities is generally interpreted by changing the equilibrium solubility or the solution structure, by adsorption or chemisorption on nuclei or heteronuclei, by chemical reaction or complex formation in the solution [18]. So far, explaination to the impurities effect on the induction period for various systems have been proposed in the literature. For $\mathrm{CaCO}_{3}$ formed by mixing solutions of $\mathrm{CaCl}_{2}$ and $\mathrm{Na}_{2} \mathrm{CO}_{3}$, Söhnel and Mullin [19] found that cations $\mathrm{K}^{+}$, $\mathrm{Cr}^{3+}$ and $\mathrm{Ni}^{+}$exert little influence on $t_{\text {ind }}$, only $\mathrm{Mn}^{2+}$ and $\mathrm{Mg}^{2+}$ lengthen the induction period. They concluded that the increase in $t_{\text {ind }}$ caused by the presence of impurity is due to an increase in the crystal-solution interfacial energy. Pokrovsky [20] also found that the induction period of $\mathrm{CaCO}_{3}$ increases with increasing the $\mathrm{Mg}^{2+} / \mathrm{Ca}^{2+}$ activity ratio in solution. They postulated that the increase in $t_{\text {ind }}$ is due to an increase in the crystal-solution interfacial energy at higher $\mathrm{Mg}^{2+} / \mathrm{Ca}^{2+}$ region and due to an increase in the activity of $\mathrm{Mg}^{2+}$ at lower $\mathrm{Mg}^{2+} /$ $\mathrm{Ca}^{2+}$ region. Therefore, we consider that the effect of $\mathrm{Mg}^{2+}$ on the induction period in our present study is caused from an increase in the interfacial energy of $\mathrm{CaCO}_{3}$. The larger interfacial energy results in a longer induction period when $\mathrm{Mg}^{2+}$ is added into the solution. On the other hand, $\mathrm{Na}^{+}$ has little influence on the interfacial energy and thus the induction period.

\section{Conclusion}

The effects of initial reagent concentration, temperature, $\mathrm{pH}$, the presence of $\mathrm{Mg}^{2+}$ or $\mathrm{Na}^{+}$, and the addition of seed on the induction period of $\mathrm{CaCO}_{3}$ are studied experimentally. The results show that the induction period increases with a decrease in initial reagent concentration, temperature, and $\mathrm{pH}$. The presence of $\mathrm{Mg}^{2+}$ in solution prolongs the induction period. On the other hand, the presence of $\mathrm{Na}^{+}$in solution has little influence on the induction period. Further, addition of seed in solution shortens the induction period. The results also showed that the present method should be applicable to many systems for determination of induction period.

\section{Acknowledgements}

This study is supported by the National Science Council of the Republic of China. 


\section{References}

[1] O. Söhnel, J.W. Mullin, J. Crystal Growth 44 (1978) 377. [2] O. Söhnel, J.W. Mullin, J. Crystal Growth 60 (1982) 239.

[3] M.I.H. Wakita, I. Masuda, J. Crystal Growth 61 (1983) 377.

[4] P.A. Carosso, E. Pelizzetti, J. Crystal Growth 68 (1984) 532.

[5] W. Kibalczyc, K. Bondarczuk, J. Crystal Growth 71 (1985) 751.

[6] A. Glasner, M. Tassa, J. Crystal Growth 13/14 (1972) 441.

[7] W. Kibalczyc, A. Zielenkiewicz, J. Crystal Growth 82 (1987) 733.

[8] M.C. van der Leeden, D. Verdoes, D. Kashchiev, G.M. van Rosmalen, in: J. Garside, et al., (Eds.), Advance in Industrial Crystallization, Butterworth, Oxford, 1991, p. 1.

[9] J. Gómez-Morales, J. Torrent-Burgués, R. RodríguezClemente, J. Crystal Growth 169 (1996) 331.
[10] O. Söhnel, J. Garside, Precipitation: Basic Principles and Industrial Applications, Butterworth, Oxford, 1992, p. 206.

[11] W.C. Chien, C.Y. Tai, J.P. Hsu, J. Chem. Phys. 111 (1999) 2657.

[12] M.S. Joshi, A.V. Antony, J. Crystal Growth 46 (1979) 7.

[13] J.W. Mullin, S. Žáček, J. Crystal Growth 53 (1981) 515.

[14] M.J. Mullin, Crystallization, Butterworth, Oxford, 1993, p. 198.

[15] R.Y. Qian, G.D. Botsaris, Chem. Eng. Sci. 52 (1997) 3429.

[16] Yu.G. Kuznetsov, A.J. Malkin, W. Glantz, A. Mcpherson, J. Crystal Growth 168 (1996) 63.

[17] ASTM Designation D513, 1974, p.416.

[18] M.J. Mullin, Crystallization, Butterworth, Oxford, 1993, p. 193.

[19] O. Söhnel, J.W. Mullin, J. Colloid Interface Sci. 123 (1988) 43.

[20] O.S. Pokrovsky, J. Crystal Growth 186 (1998) 233. 